\title{
Luiz Vilela - O filho de Machado de Assis
}

Rio de Janeiro: Record, 2016

Pauliane Amaral ${ }^{1}$

Em entrevista concedida recentemente, o escritor Luiz Vilela, discorrendo sobre a escassa recepção da obra dos colegas Roberto Drummond, Oswaldo França Júnior e Wander Piroli, diz: "É triste, o escritor morre e vem logo o esquecimento" (Vilela, 2017, s.p.). Tal afirmação, no entanto, é oposta à premissa de sua mais recente novela, O filho de Machado de Assis (2016), cujo argumento central da narrativa sugere que um grande autor não só pode continuar vivo através de sua obra, como também dar origem a um culto à sua figura, ressuscitada de tempos em tempos por outros escritores (como o faz o próprio Vilela no livro em questão) e pelos estudiosos e críticos da área. Há pouco tempo, o escritor e crítico literário Silviano Santiago (2016) também lançou um romance ensaístico sobre o Bruxo do Cosme Velho, intitulado Machado. Em sua resenha, Davi Andrade Pimentel indica que o livro de Santiago "se deseja ao mesmo tempo ensaístico, historiográfico, ficcional e com pinceladas de crônica de costumes" (Pimentel, 2017, p. 307). Nesse sentido, a novela de Luiz Vilela é mais convencional quanto à forma e seu objeto é a reflexão sobre a compreensão romântica do autor como gênio intocável, um ser sagrado. A obra desenvolve temas machadianos como a relação entre a loucura e a literatura, e o uso da ironia como força propulsora da crítica de costumes.

A loucura, por exemplo, evidencia-se em dois pontos significativos da novela: no histrionismo do professor Simão, o protagonista cujo nome faz referência à personagem machadiana de Simão Bacamarte, em O Alienista (1882); e em uma analepse em que Mac - aluno de Simão e narrador da novela - recorda a história de outro professor seu, chamado Padre Ludovico (Vilela, 2016, p. 23-27), que acabou internado em uma clínica para doentes mentais. Essas são pistas que podem levar o leitor a desconfiar da veracidade da descoberta de um suposto filho Machado de Assis - elemento central de toda a narrativa. Em uma de suas falas, Professor Simão revela que não pode duvidar do sujeito que falou sobre

\footnotetext{
${ }^{1}$ Doutoranda em letras na Universidade Federal de Mato Grosso do Sul (UFMS), Três Lagoas, MS, Brasil. Dorcid.org/0000-0002-6718-4524. E-mail: paulianeamaral@gmail.com
} 
a existência do tal filho: "Se eu duvidar, eu não tenho como prosseguir minha pesquisa" (Vilela, 2016, p. 56).

A suposta descoberta de um filho de Machado de Assis feita pelo professor é ponto de partida para reflexões sobre a discrepância entre a figura pública e a vida privada de escritores famosos. Entre os casos citados, está o do alemão Günter Grass, que ocultou ter participado da juventude hitlerista, e o de Arthur Miller, que escondeu ter um filho com síndrome de Down. O motivo do filho de Machado de Assis ter sido ocultado pelo escritor, na ficção, é que, além ser fruto de uma aventura anterior a seu casamento com Carolina, o menino também era negro, e Machado teria pensado ser mais fácil escondê-lo do que enfrentar o preconceito social. Escrutinadora e atrevida, a narrativa da novela de Luiz Vilela mostra em diversos trechos a importância de dessacralizar a figura humana do autor, para deixá-lo viver somente no texto, talvez através do que Wayne C. Booth (2010) classificou como autor implícito.

Mais do que a herança de Machado de Assis para a literatura brasileira, na narrativa de Luiz Vilela, o debate sobre a relação entre o escritor e sua obra é fundamental, na medida em que reafirma a necessidade de livrar o texto literário de uma interpretação biografista. O anticlímax do desfecho da novela mostra que o autor implícito se esforça em deixar claro que sua opinião é de que a revelação de novos dados biográficos não muda a forma de se ler uma obra, pois o valor dessa reside em suas qualidades literárias, que nada têm a ver com as qualidades éticas e morais de um escritor. Argumentando pelo fim do exagero que circunscreve o tema "gênio versus destino", Antonio Candido lembra que, impulsionados pela biografia de Lúcia Miguel Pereira, os críticos de Machado de Assis anteriores aos estudos renovadores de Jean-Michel Massa "nunca deixaram de inventariar e realçar as causas eventuais de tormento, social e individual: cor escura, origem humilde, carreira difícil, humilhações, doença nervosa" (Candido, 2011, p. 15) para de algum modo explicar a obra do autor.

Quanto à forma da novela O filho de Machado de Assis, convém apontar para as elipses que são viabilizadas pela adoção do ponto de vista de um narrador homodiegético, o estudante Mac - apelido para Telêmaco -, que relata a descoberta do seu mestre mesmo sem ter sobre ela todos os detalhes. Esse ponto de vista restritivo potencializa o suspense da narrativa, pois permite que detalhes importantes sejam omitidos. Mais uma vez, Luiz Vilela privilegia o diálogo, o discurso 
direto, como técnica para apresentar a ação e a psicologia das personagens. O tempo da diegese é extremamente sucinto e praticamente todo o enredo se passa em uma manhã de sábado.

Novela de enredo, O filho de Machado de Assis parte de uma auspiciosa premissa, mas parece perder sua força em trechos em que o banal invade as digressões do narrador. Um exemplo desse modus operandi, visto também em outras narrativas do autor, é o trecho em que Mac divaga sobre competições absurdas (de "tlec", de cuspe a distância e até de "pum"). São desvios como esse que fazem com que o leitor se pergunte qual é o saldo desse tipo de divagação na dinâmica da narrativa. Até que ponto a inserção de um tema que não está relacionado - a não ser do modo muito elíptico e obscuro - à narrativa principal pode tolher a pujança da narrativa? Essa é uma reflexão árdua, que transborda os limites dessa resenha, mas, a princípio, temos a impressão de que uma divagação sobre algo banal tem um efeito menor (em termos de geração de significado para a narrativa) do que, por exemplo, a exploração de temas correlatos à história principal da narrativa.

A fatura de humor também está presente na narrativa de $O$ filho de Machado de Assis de diversas maneiras. Há uma camada de ironia intertextual, ${ }^{2}$ indicada já no nome do protagonista e no uso do grau superlativo como uma das características que marcam a fala do professor "Como diria a Professor Simão: Claríssimo" (Vilela, 2016, p. 56, grifo nosso) -, em uma referência ao inesquecível trejeito linguístico do agregado José Dias, personagem de Dom Casmurro (1900). Também há sátira, de substrato moralizante e riso malévolo resultante da exposição da ignorância daqueles que desconhecem Machado, a exemplo da história da moça que diz que Machado de Assis teve não um filho, mas uma filha, e que ela se chamava Carolina, ou na conversa entre o professor e o taxista que era a cara do escritor, e que quando perguntado se conhece Machado de Assis, responde: "Claro [...] eu já transportei o doutor Machado muitas vezes" (Vilela, 2016, p. 63). Há ainda o humor fácil que nasce das implicações do professor Simão com o politicamente correto.

Anacrônico e de personalidade exaltada, Simão faz previsões pessimistas sobre o futuro da literatura, o que não o impede de ver na descoberta de um filho de Machado de Assis um grande evento, "uma

${ }^{2}$ Conceito de Umberto Eco (2003) que se refere a citações diretas de outros textos famosos ou referência a eles, de maneira mais ou menos transparentes. 
descoberta simplesmente monumental", "uma descoberta transcendental" (Vilela, 2016, p. 17) que o tornará famoso e terá grande impacto no mundo das letras. "[G]ente que escreveu livros inteiros explicando a obra do Bruxo pela ausência de filhos... E agora, com que cara eles vão ficar?" (Vilela, 2016, p. 22). O exagero na crítica ao biografismo e a vontade de se tornar imortal entre os estudiosos das letras através de uma descoberta biográfica resulta em um paradoxo e deixa implícita a visão irônica do autor sobre o tema da vaidade humana.

Morando em um sobrado em Santa Tereza, solteirão e sem filhos, Professor Simão compartilha as mesmas características de outros de personagens centrais na obra de Luiz Vilela, a exemplo de Nei, de Os novos (1971), Edgar, de O inferno é aqui mesmo (1979), Ezequiel, de Entre amigos (1983), Epifânio, de Graça (1989) e Ramon, de Perdição (2011), para atermo-nos apenas aos romances. Eles são homens, brancos, de classe média, que tem na escrita sua fonte de renda ou de prazer, quando não os dois. Ao que parece, Luiz Vilela, seguindo a receita de Tolstoi, continua a pintar os tipos de sua aldeia.

A revelação de uma falsa descoberta seria um anticlímax e outro fim possível da novela, se o enredo continuasse com Mac procurando pelos últimos documentos consultados por seu mestre em seu cadastro na Biblioteca Nacional, lugar no qual o professor diz estar o documento que comprova o nascimento do filho de Machado de Assis. Uma das preocupações do protagonista é a de que, durante o feriado de fim de ano, quando a biblioteca fecha ao público, o prédio pegue fogo e ponha fim à sua "grande descoberta". No fim da narrativa, os livros de uma biblioteca serão queimados, mas não os da Biblioteca Nacional. A queima de livros - imagem que já foi utilizada como símbolo da repressão no romance Fahrenheit 451 (1953), de Ray Bradbury - aqui parece denotar o declínio das letras no mundo contemporâneo.

Há também um conflito de gerações nas entrelinhas da novela. Mac e Simão são as duas pontas de uma geração de leitores de literatura. Quando professor Simão diz que Mac poderá ser seu sucessor, o jovem mensura: "trocar o sol das manhãs ou das tardes de praia, as gatas, a água de coco, trocar tudo isso pela luz artificial das salas de biblioteca, funcionárias feias e carrancudas, o mofo das estantes de livros" (Vilela, 2016, p. 35). O desfecho da narrativa é muito mais direto quanto ao que se pode chamar de fim da cultura letrada no país. Em entrevista recentemente concedida, cogitando sobre o lugar da literatura no século 
XXI, numa sociedade dominada pela cultura de massa, pelas novas mídias e pela economia de mercado, Luiz Vilela não disfarça seu pessimismo: "eu acho que enquanto existir o homem existirá a literatura. Bem, eu talvez não ache tanto assim" (Vilela, 2017, s.p.).

Se Machado de Assis "recobria os seus livros com a cutícula do respeito humano e das boas maneiras para poder, debaixo dela, desmascarar, investigar, experimentar, descobrir o mundo da alma, rir da sociedade" (Candido, 2011, p. 18), Luiz Vilela opta pela sátira explícita, ri com escárnio tanto daqueles afeitos às idolatrias, como daqueles que ignoram um nome tão importante para as letras brasileiras como Machado de Assis. O riso que ecoa da narrativa de $O$ filho de Machado de Assis, assim como a personalidade de seu protagonista, é histriônico, tende ao exagero. $\mathrm{O}$ tema da idolatria carrega em si o questionamento dos limites entre a razão e a loucura que, como já observou Candido (2011, p. 23), é uma preocupação que percorre a obra de Machado de Assis.

Em um mundo em que tudo se inclina ao banal, em que a própria vida parece descartável, a narrativa de Vilela se junta ao coro das vozes "insanas" que profetizam o fim da literatura. Sua novela, cujo enredo é impulsionado por uma descoberta circunstancial, tão ordinária para uns e tão importante para outros, leva-nos a refletir sobre o peso do banal no mundo contemporâneo e na própria crítica literária. Quanto ao peso que a vida de um escritor pode ter na interpretação de sua obra, a narrativa de $O$ filho de Machado de Assis deixa claro que toda biografia não deixa de ser uma forma de transformação do homem em objeto do homem.

\section{Referências}

ASSIS, Machado de (1882). O alienista. In: ASSIS, Machado de. Papéis avulsos. Rio de Janeiro: Lombaerts \& Cia.

ASSIS, Machado de (1900). Dom Casmurro. Rio de Janeiro: Garnier.

BOOTH, Wayne C. (2010). The rhetoric of fiction. Chicago: University of Chicago Press.

BRADBURY, Ray (1953). Fahrenheit 451: a novel. New York: Ballantine.

CANDIDO, Antonio (2011). Esquema de Machado de Assis. In: CANDIDO, Antonio. Vários escritos. 4. ed. Rio de Janeiro: Ouro sobre Azul. p. 15-33. 
ECO, Umberto (2003). Ironia intertextual e níveis de leitura. In: ECO, Umberto. Sobre a literatura. Tradução de Sulla letteratura. Rio de Janeiro: Record. p. 199-218.

PIMENTEL, Davi Andrade (2017). Silviano Santiago - Machado. Estudos de Literatura Brasileira Contemporânea, Brasília, n. 51, p. 307-312. Disponível em: <https://goo.gl/7g8WpK>. Acesso em: 30 maio 2017.

SANTIAGO, Silviano (2016). Machado. São Paulo: Companhia das Letras

VILELA, Luiz (1971) Os novos. Rio de Janeiro: Gernasa.

VILELA, Luiz (1979) O inferno é aqui mesmo. São Paulo: Ática.

VILELA, Luiz (1983) Entre amigos. São Paulo: Ática.

VILELA, Luiz (1989) Graça. São Paulo: Estação Liberdade.

VILELA, Luiz (2011). Perdição. Rio de Janeiro: Record.

VILELA, Luiz (2016). O filho de Machado de Assis. Rio de Janeiro: Record.

VILELA, Luiz (2017). Escrever é a minha cachaça. Entrevista a Daniel de Mesquita Benevides. PáginaB!, [S.l.], 16 abr. On-line. Disponível em: <https://goo.gl/VGZPUC>. Acesso em: 30 maio 2017.

Recebido em 30 de maio de 2017.

Aprovado em 31 de janeiro de 2018. 